\title{
HUNIAN CERDAS
}

\author{
Malvin $\mathrm{Ng}{ }^{1)}$, Tatang $\mathrm{H}$. Pangestu ${ }^{2)}$ \\ 1)Program Studi S1 Arsitektur, Fakultas Teknik, Universitas Tarumanagara, malvinmalvin.ngng@gmail.com \\ 2) Program Studi S1 Arsitektur, Fakultas Teknik, Universitas Tarumanagara, tatang_pangestu@hotmail.com
}

\begin{abstract}
Abstrak
Pada saat ini manusia memilki suatu pola kegiatan yang mengutamakan serba instan. Kehidupan lingkungan keras dan penuh ambisi. Karena hal itu menurut mereka suatu pekerjaan keras itu yang membuat waktu begitu berharga buat semua nya. Efisien dalam bertindak merupakan tindakan yang wajib saat ini. Pemiihan keputusan dalam hal apapun menjadi pertanggung yang mencoba kegampangan dalam beraktivitas. Seagala macam bidang pekerjaan ingin di laksanakan dengan instan dan terlihat hasil nya. Manusia adalah suatu ciptaan yang ingin mengetahui segala sesuatu nya. Segala sesuatu nya tak akan pernah puas. Manusia harus bekerja jawaban yg besar. Namun banyak orang yang memilih cara nya sendiri yang instan tanpa mengetahui dampak untuk sekitar nya. Bukan hanya dalam pekerjaan namun gaya hidup manusia lebih cenderung untuk terlihat lebih inovatif, kreatif, independent, dan pasti nya instan.
\end{abstract}

Kata kunci: Edukasi; Gaya Hidup; Hunian; Milenial

\begin{abstract}
At this time humans have a pattern of activities that prioritize all things instantaneously. Hard and Full Environmental Life. Because it fits their work, it makes time so valuable for all. Efficient in action is mandatory at this time. Decision making in any case becomes a responsibility that tries to be easy in doing activities. Even if the type of work area wants to be implemented instantly and the results are visible. Man is a creation that wants to know everything. Everything will never be satisfied. People must work to answer the big one. But many people choose their own instant way without knowing how to get around. Not only in work but the human lifestyle is preferred to look more innovative, creative, independent, and definitely instant.
\end{abstract}

Keywords: Education; Housing; Lifestyle; Millennial

\section{PENDAHULUAN}

Generasi Milenial atau yang beberapa orang menyebutnya Generasi $Y$ sebagian besar dianggap sebagai sekelompok orang yang lahir antara tahun 1980-2000. Generasi milenium telah menjadi dewasa selama masa perubahan teknologi, globalisasi, dan gangguan ekonomi. Itu memberi mereka serangkaian perilaku dan pengalaman yang berbeda dari orang tua mereka.

"Generasi Millenial tidak seperti generasi muda lainnya. Mereka lebih banyak, lebih kaya, lebih berpendidikan, dan lebih beragam secara etnis. Lebih penting lagi, mereka mulai memanifestasikan beragam kebiasaan sosial positif yang tidak lagi diasosiasikan dengan orang tua dengan kaum muda, termasuk fokus baru pada kerja tim, prestasi, kesederhanaan, dan perilaku yang baik. "- Neil Howe dan William Strauss

Perkembangan teknologi yang sangat pesat ini sangat berpengaruh pada berbagai bidang kehidupan manusia millennial. Pada akhirnya memunculkan inovasi- inovasi yang unik dan baru pada bidang IT, pendidikan, mileter, perdagangan, dan otomotif. Perkembangan teknologi tersebut untuk mempermudah kegiatan yang di lakukan, salah satunya dalam belajar, dimana belajar merupakan sesuatu kebutukan manusia yang dasar.

Belajar adalah perubahan yang relatif permanen dalam perilaku atau potensi perilaku sebagai hasil dari pengalaman atau latihan yang diperkuat. Belajar merupakan akibat adanya 
interaksi antara stimulus dan respon. Seseorang dianggap telah belajar sesuatu jika dia dapat menunjukkan perubahan perilakunya. Menurut teori ini, dalam belajar yang penting adalah input yang berupa stimulus dan output yang berupa respons.

Pada masa millennial ini belajar formal sudah sangat kuno dan lambat, era digitalisasi ini mendorong perkembangan pendidikan menjadi lebih maju dan berbasis teknologi canggih. Melalui teknologi pembelajaran para pendidik akan mudah melakukan simulasi pembelajaran mendekati kondisi nyata dari suatu materi pembelajaran yang abstrak

\section{KAJIAN LITERATUR}

Metode yang digunakan dalam pencarian data untuk pembuatan jurnal ini adalah :

- Pencarian data artikel yang ada di buku dan majalah

- Pencarian data dari internet tentang Smart Living

- Pencarian data dari internet mengenai tempat tempat yang berhubungan dengan Smart Living

- Survey

\section{Kajian Tentang Millenial}

Milenial adalah sebuah kelompok demografi setelah Generasi $X$. Para penelit biasa nya menggunkan awal tahun 1980-an sebagai awal mula nya lahir kelompok ini dan pada pertengahan 1990-an hingga awal 2000-an sebagai akhir kelompok ini .

Milenial yang biasa di sebut Generasi Y merupakan generasi yang " Echo Boomers " karena terjadi nya booming pada tahun 1980-an dan 1990-an . Karakteristik Milenial lebih terkesan individual , cukup mengabaikan masalah politik , fokus pada nilai nilai materialistis, dan kurang peduli dengan sesama jika di bandingkan dengan generasi generasi sebelum nya. Generasi Milenial adalah generasi yang pemalas, narsis, dan suka melompat dari satu pekerjaan ke pekerjaan yang lain .

Selain itu Generasi Milenial merupakan generasi yang memeiliki pemikiran yang terbuka, pendukung kesetaraan hak (LGBT atau kaum minoritas), kepercayaan diri yang bagus, mampu mengekspresikan perasaannya, pribadi yang optimis, liberal, dan menerima ide ide dan cara cara hidup.

Karena Milenial berkisar mulai dari tahun 1980-an, sehingga orang dengan kelompok umur 37thn - 24thn menjadi kelompok umur yang sedang bergerak dalam kegiatan dalam semua bidang pekerjaan dan kegiatan. Pada masa masa ini semua kegiatan di dominasi oleh generasi milenial. Dalam hal ini generasi milenial mempunyai dampak yang postif dan tentu negatif.

Dampak Postif :

- Multitasking

- Kreativitas di hargai

- Lebih Kritis

- Bisa berkontribusi dengan cara yang berbeda

Namun memiliki dampak Negatf :

- Pengen semua seeba instan

- Kurang etika

- Cenderung permisif

- Social skill kurang

Generasi milenial inilah juga yang ke depannya akan menjadi pemutar roda ekonomi Indonesia karena mereka adalah konsumen terbesar dari semua produk maupun jasa. Apabila kita menengok perekonomian Indonesia yang masih didorong oleh tingginya proporsi konsumsi rumah tangga (household consumption) dan investasi terhadap pertumbuhan ekonomi, dapat diketahui bahwa generasi milenial ini akan menjadi turbin yang mendorong pertumbuhan ekonomi Indonesia pada tahun 2020-2030 mendatang. Di Indonesia sendiri teknologi merupakan suatu hal yang tidak bisa dilepaskan oleh masyarakat Indonesia, 
terutama bagi mereka yang lahir pada generasi $Y$, dan generasi penerus mereka, sebab teknologi merupakan sesuatu yang mereka gunakan sehari-hari sedari kecil. Kedepannya, penulis memproyeksikan bahwa penggunaan teknologi masih akan prevalen di kalangan masyarakat dan bahkan akan semakin sering digunakan, mengingat berbagai teknologi pembayaran yang ada seperti $e$-wallet, e-banking, e-payment dan sebagainya semakin populer belakangan ini sehingga akan menggeser transaksi konvensional.

Salah satu perubahan signifikan yang dibawa oleh generasi ini adalah perubahan preferensi gaya hidup dan persepsi terhadap hal-hal seputar finansial. Untuk gaya hidup, generasi milenial ini lebih mengutamakan faktor kepraktisan di atas segalanya dalam sebuah pengambilan keputusan. Misalnya, generasi ini akan lebih memilih membeli apartemen di tengah kota daripada membeli sebuah rumah tapak di pinggiran kota (suburb) apabila hal tersebut memudahkan mereka untuk mencapai tempat kerja, mereka juga memilih tempat tinggal yang memiliki fasilitas memadai, seperti kolam renang ataupun tempat kebugaran (gym), dekat dengan pusat perbelanjaan, dan sebagainya.

\section{Kajian Tentang Hunian}

Menurut Turner (1972:164-167), terdapat tiga fungsi yang terkandung dalam rumah:

1. Rumah sebagai penunjang identitas keluarga, yang diwujudkan dalam kualitas hunian atau perlindungan yang diberian rumah. Kebutuhan tempat tinggal dimaksudkan agar penghuni mempunyai tempat tinggal atau berteduh secukupnya untuk melindungi keluarga dari iklim setempat.

2. Rumah sebagai penunjang kesempatan keluarga untuk berkembang dalam kehidupan sosial, budaya, dan ekonomi atau fungsi pengembangan keluarga. Fungsi ini diwudkan dalam lokasi tempat rumah itu didirikan. Kebutuhan berupa akses ini diterjemahkan dalam pemenuhan kebutuhan sosial dan kemudahan ke tempat kerja guna mendapatkan sumber penghasilan.

Rumah sebagai penunjang rasa aman dalam arti terjaminnya kehidupan keluarga di masa depan setelah mendapatkan rumah, jaminan keamanan lingkungan perumahan yang ditempati serta jaminan keamanan berupa kepemilikan rumah dan lahan.

Rumah sebagai kebutuhan dasar manusia, perwujudannya bervariasi menurut siapa penghuni atau pemiliknya. Berdasarkan hierarchy of need (Maslow, 1954:10), kebutuhan akan rumah dapat didekati sebagai:

- Physiological needs (kebutuhan akan makan dan minum), merupakan kebutuhan biologis yang hampir sama untuk setiap orang, yang juga merupakan kebuthan terpenting selain rumah, sandang, dan pangan juga termasuk dalam tahap ini.

- Safety or security needs (kebutuhan akan keamanan),merupakan tempat berlindung bagi penghuni dari gangguan manusia dan lingkungan yang tidak diinginkan.

- Social or afiliation needs (kebutuhan berinteraksi), sebagai tempat untuk berinteraksi dengan keluarga dan teman.

- Self actualiztion needs (kebutuhan akan ekspresi diri), rumah bukan hanya sebagai tempat tinggal, tetapi menjadi tempat untuk mengaktualisasikan diri.

\section{Perkembangan Hunian}

Pada Era Millenials ini perkembangan rumah / bentuk hunian lebih mengarah ke Era Minimalis atau Town House .Yang di maksud Gaya Perkotaan/Minimalis :

a Kesadaran akan ruang

b Ruang Terbuka

c Rapi dan Sederhana

d Material dan Karakteristik Alami

e Bahan Bangunan Hijau (Green building materials)

f Biaya Perawatan yang Rendah 


\section{g Smart Teknologi}

Arsitek-arsitek pada generasi milenial memiliki banyak banyak sekali inovatif inovatif untuk memulai konsep pada suatu bangunan. Namun pada saat ini ada beberapa trend yang sedang berkembang di generasi milenial ini. Beberapa tren tersebut di antara nya seperti berikut :

- Trend Arsitektur Futuristik

- Trend Arsitektur Retro dan Vintage

- Trend Arsitektur Industrial

- Trend Arsitektur All-Black

- Trend Arsitektur Back to Nature

- Trend Arsitektur Minimalis

\section{Kajian Tentang Smart Living}

Gambaran Umum akan Smart Living :

- Membangun smart living di area mereka sebagai sesuatu yang dibutuhkan. Lingkungan bersih, aman, kuliner banyak tersedia, rumah sakit, bank serta fasilitas hiburan. Menyediakan apa yang tidak didapatkan di rumah.

- Hunian yang sehat harus memiliki sistem ventilasi yang baik di mana aliran udara dapat dengan mudah keluar masuk rumah. Tak hanya itu, banyak rumah dengan konsep smart living memiliki jendela kaca besar sehingga pencahayaan alami didapatkan di siang hari dan mengurangi pemakaian listrik. Sinar matahari diketahui baik bagi kesehatan pemilik dan rumah itu sendiri. Sistem drainase dan tempat pembuangan sampah pun harus diperhatikan. Pasalnya, hunian sehat tak hanya menyehatkan sang pemilik rumah, namun harus juga menyehatkan orang dan lingkungan sekitar.

- Harus mengoperasikan sekaligus dengan remote control dan akses internet. Seakan berlari, teknologi terus melaju pesat tanpa bisa dihentikan. Teknologi ini hadir menjawab kebutuhan manusia yang dulu sulit terpenuhi.

- Efisien berarti semua ruangan memiliki fungsi masing-masing dan tidak ada satu pun sudut rumah yang tidak terpakai atau dibiarkan kosong. Salah satu contoh yaitu adanya kamar tamu. Seringkali kamar tamu hanya digunakan sesekali.

Sehingga Konsep Smart Living di rasa sangat tepat. Terutama untuk gaya hidup milenialls ini . Selain berdampak untuk penghuni nya dari Konsep Smart Living ini muncul beberapa konsep yang nanti nya membantu untuk pertumbuhan kota ini, seperti menciptkan Smart People, Smart Economy, Smart Environtment, Smart Mobility, Smart Goverment, dan akhir nya menjadi Smart City. Smart Living ini juga harus memikirkan Green Lifestyle yang dapat memberikan kehidupan yang lebih baik bagi lingkungan dan generasi mendatang.

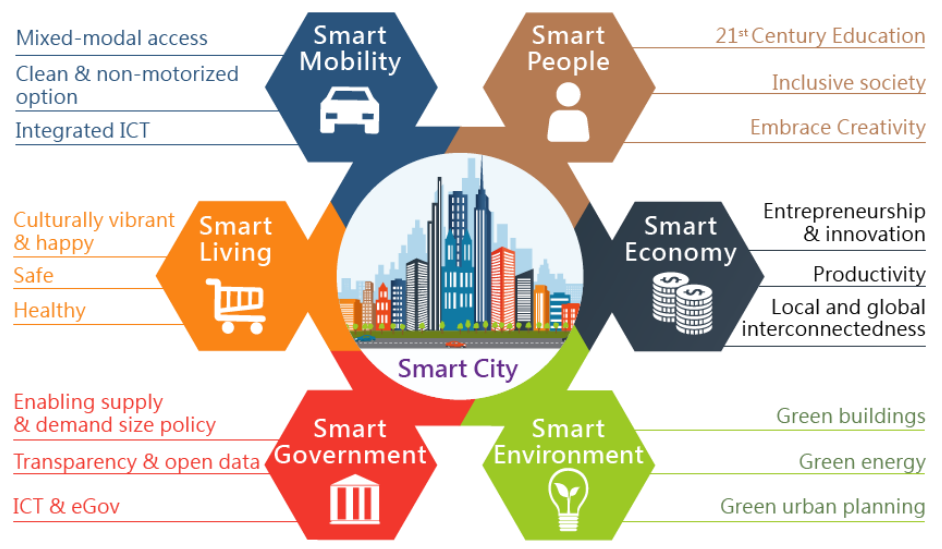

Gambar 1. Diagram Smart City

Sumber: Google , 2019 


\section{DISKUSI DAN HASIL}

Smart Living Housing berlokasi di Jl. Dharma Griya Raya No2, RT.2/RW.11, Duri Kosambi,Cengkareng, Kota Jakarta Barat, Daerah Khusus Ibukota Jakarta 11750. Proyek ini berfungsi sebagai berikut Hunian yang memberikan kenyamanan dengan beberapa fasilitas yang mendukung kegiatan kegiatan untuk para millenial untuk lebih produktif. Tapak dengan luas $8000 \mathrm{~m}^{2}$ dengan 70 persen sebagai program utama berupa hunian.

Fasilitas pada tapak di gunakan untuk penhuni apartment agar dapat menunjang kegiatan keseharian mereka yang di butuhkan agar kebutuhan para milenialis ini terpenuhi oleh hunian ini . Terdapat beberapa pintu masuk yang dapat di akses dengan jalan kaki maupun kendaraan bermotor. Tapak yang memiliki danau di dalam nya memiliki keuntungan dan menjadi suatu titik penting utama agar dapat di kelola dengan baik dan benar. Hal itu yang menyebabkan orientasi tapak menjadi menuju dan mendukung ke arah danau tersebut. Danau tersebut dapat di jadikan banyak hal. Sebagai tempat berkumpul, menjadi jogging track, menjadi tempat yang luas untuk beraktivitas olahraga.

Kolam renang pada tapak menjadi sebuah fasilitas penunjang yang paling besar pada tapak ini , karena kolam renang di design agar dibuat untuk menunjang danau sebagai sarana olahrga yang lebih menarik dengan tema yang sama dengan kolam tersebut .

Program pada tapak di tujukan agar para penghuni apartment di tujukan untuk berjalan kaki dan menuju trasnportasi umun yang ada dan pada jalur pejalan kaki di posisi timur lebih di tujukan untuk para penghuni untuk menggunakan transportasi online.

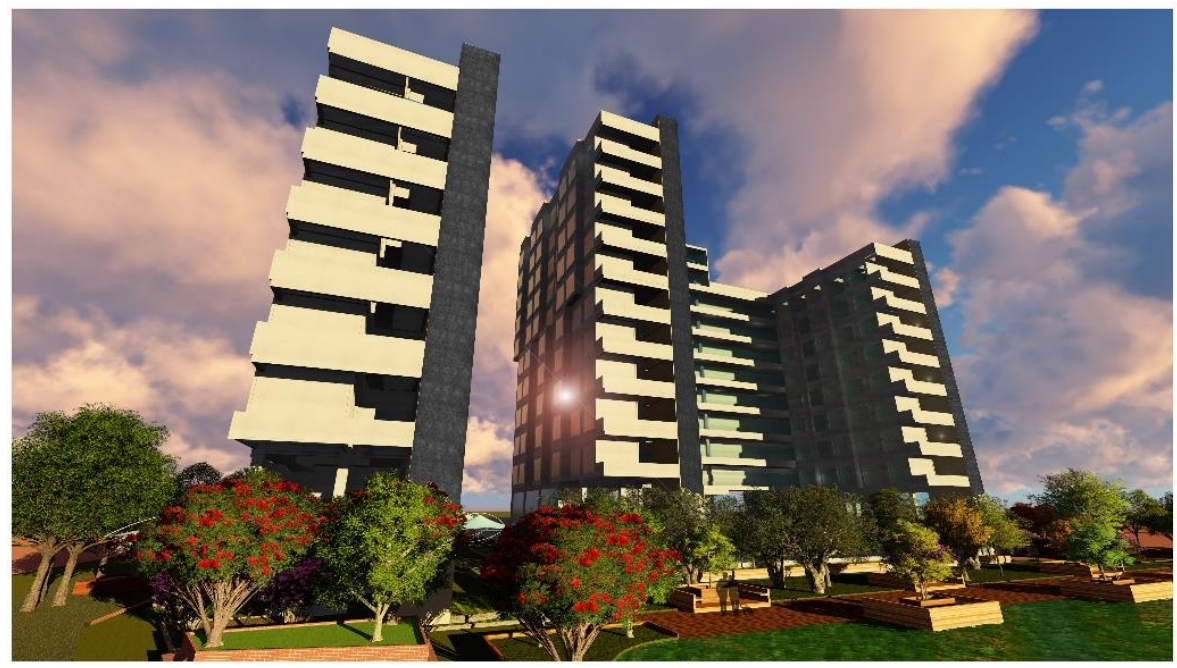

Gambar 1. Perspektif Eksterior

Sumber: Penulis, 2019
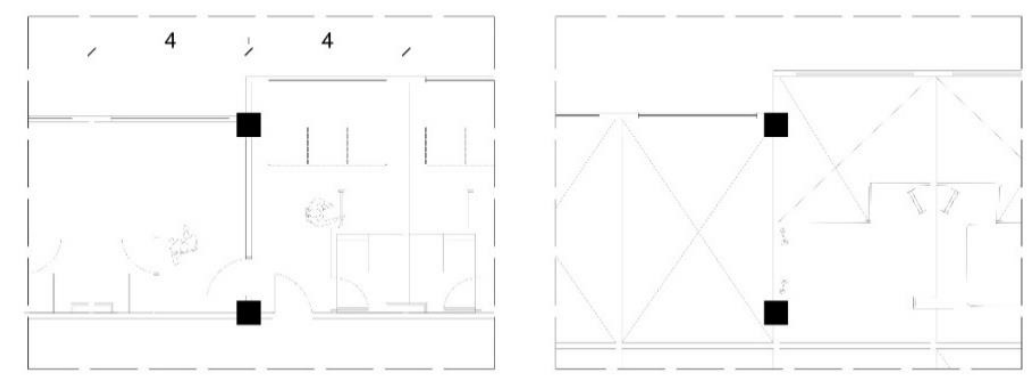

$\boldsymbol{7}^{\text {DENAH UNIT }}$

DENAH UNIT MEZANINE

Gambar 2. Denah

Sumber: Penulis, 2019 
Denah Unit terdiri dari 3 tipe ruang yaitu ukuran $24 \mathrm{~m}^{2}, 28 \mathrm{~m}^{2}$ dan $52 \mathrm{~m}^{2}$. Setiap luasan unit memilik fungsi dan kebutuhan masing masing. Untuk unit yang terkecil di kususkan untuk para milenial yang memiliki kesibukan yang luar biasa kesibukan dan unit unit kecil ini di maximalkan untuk di gunakan se-maksimal mungkin untuk semua kegiatan yang di butuhkan.

Perbedaan unit unit lain nya adalah dalam tata letak perabotan yang di gunakan, untuk unit $52 \mathrm{~m}^{2}$ digunakan biasa nya lebih di tujukan untuk keluarga yang setidak nya memiliki 2 anak.

Unit juga di lengkapi dengan perabotan perabotan yang memiliki kesan minimalis dan futuristik. Perabotan di usahakan menjadi perabotan perabotan yang portable dan fungsional.
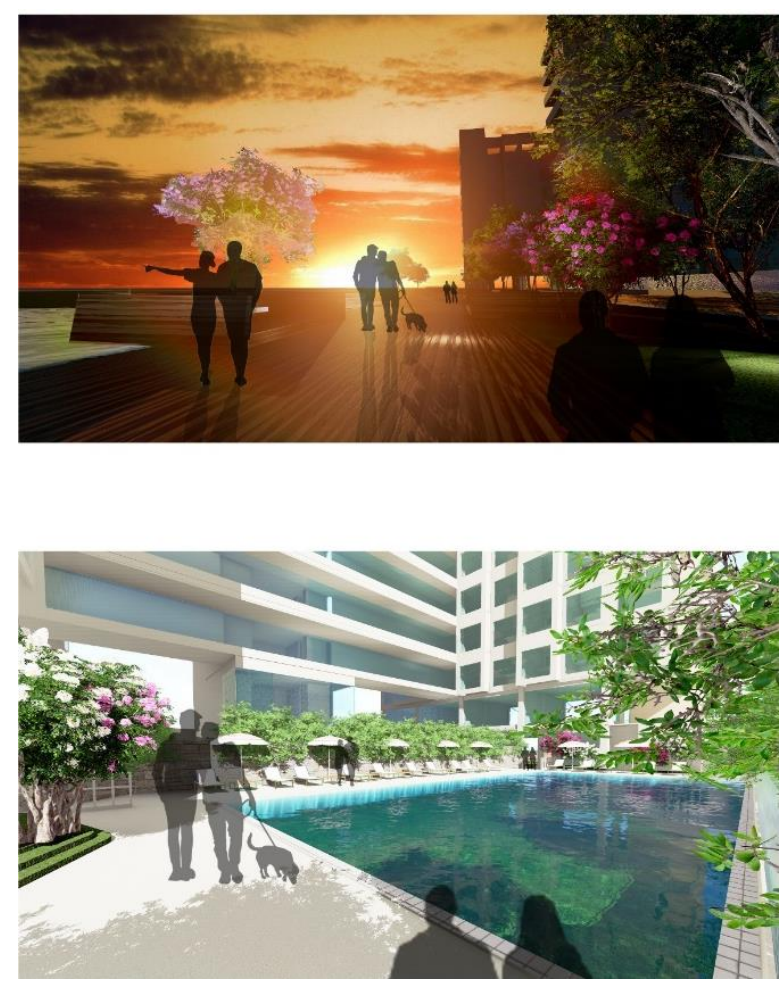

Gambar 3. Perspektif Eksterior

Sumber: Penulis, 2019

Suasana dalam bangunan yang di ciptakan begitu modern minimalis memerikan sentuhan setipa unit yang praktis, namun dapat membuat hunian menjadi lebih fungsional.

Smart Living Housing ini mempunyai 3 tower .Yang masing masing tower memiliki unit unit yang memiliki variasi unit yang beragam . Unit dapat menampung berbagai kalagang umur. Ada unit yang hanya bisa menampung para remaja Millenial yang membutuhkan kepraktisan dalam beraktivitas. Dan unit yang dpaat menampung keluarga baru yang masih sibuk dengan aktivitas kerja.

\section{KESIMPULAN DAN SARAN}

Hunian yang dapat di jadikan tempat aktivitas, suatu meeting point, suatu tempat tinggal yang di rasa cocok juga menjadi lingkungan kerja mereka. Konsep "Smart Living Housing" ini menyediakan hunian yang nyaman dan praktis. Hunian yang yang setiap unit kecil nya dapat membuat penghuninya merasa nyaman dan terpenuhi kebutuhan nya. Karena dengan Konsep 
"Smart Living Housing" ini muncul pula beberapa konsep yang nanti nya membantu untuk pertumbuhan kota ini, seperti menciptakan Smart People, Smart Economy, Smart Envirotment, Smart Mobility, Smart Goverment yang nanti nya menciptkan sebuah Smart City. Dimana Smart Living Housing ini menjadikan cikal bakal yang membuat kota ini menjadi lebih baik dari segala macam aspek - aspek tersebut. Smart Living ini juga harus memikirkan Green Lifestyle yang dapat memberikan kehidupan yang lebih baik bagi lingkungan dan generasi mendatang.

Konsep seperti ini pada masa kedepan akan sangat di nikmati dei kemudian hari . sebaik nya konsep seperti ini di buat dalam skala makro untuk membantu pemerintah memajukan generasi berikut nya dalam kehidupan bersosial, beraktivitas dan ber ekonomi .

\section{REFERENSI}

Adityo, A. (2018) Mari Terapkan Konsep Smart Living pada Hunian Anda . https://www.spacestock.com/blog/mari-terapkan-konsep-smart-living-pada-huniananda/

European Union . (2014). Smart construction products and processes.

Gambaran Besar Harga Tanah di Jakarta (diakses Desember 2018 ) https://finance.detik.com/properti/d-3050228/gambaran-besar-harga-tanah-dijakarta

Lopez, N. (2017, April 1). Gen Y: Millennials in Architecture. (di akses Desember 2018 ) https://medium.com/studiotmd/gen-y-millennials-in-architecture-476e9839321b

Michael, P. K. (2016). Perancangan Furnitur Berbahan Olahan Rotan Berbasis Smart Living Untuk Apartemen SOHO

Nielsen. (2017). millennials on millennial : A Look At Viewing Behavior, Distraction And Social Media Stars (di akses Desember 2018) www.nielsen.com/us/en/insights/news/2017/millennials-on-millennials-a-look-atviewing-behavior-distraction-social-media-stars.html

Peraturan Daerah Jakarta . (2013). Ibu Kota Jakarta.

Planner Notes. (2016) . Smart City : Smart Living

http://plannernotes.blogspot.com/2016/07/smart-city-smart-living.html 
